\title{
Efektivitas Antibiotik Golongan Sefalosporin Generasi Ke-3 Dibandingkan Fluroquinolon Terhadap Pasien Infeksi Saluran Kemih di RS PKU Muhammadiyah Yogyakarta
}

\author{
FF Baso', D A Perwitasari' dan I Risdiana² \\ ${ }^{1}$ Fakultas Farmasi Universitas Ahmad Dahlan, Yogyakarta \\ 2 PKU Muhammadiyah Gamping, Yogyakarta
}

Korespondensi: F F Baso

Email: fajrul.410@gmail.com

\begin{abstract}
ABSTRAK: Salah satu penyakit infeksi yang banyak dijumpai di rumah sakit adalah infeksi saluran kemih. Pemilihan antibiotik yang tidak tepat dapat menyebabkan pertumbuhan resistensi dan multipel resistensi mikroba terhadap antibiotik yang berdampak pada meningkatnya morbiditas, mortalitas, dan biaya kesehatan. Penelitian ini bertujuan untuk mengevaluasi efektivitas dan perbandingan lama rawat inap antibiotik golongan sefalosporin generasi ke-3 dan fluoroquinolon di instalasi rawat inap RS PKU Muhammadiyah Yogyakarta. Penelitian ini menggunakan rancangan kohort retrospektif pada pasien ISK periode Januari 2015 - Desember 2017. Semua data pasien yang memenuhi kriteria inklusi diambil dari catatan rekam medis pasien. Berdasarkan hasil penelitian, sebanyak 66 pasien ISK, 90,9\% didominasi oleh perempuan dan 53\% didominasi oleh kelompok berumur $>60$ tahun. Kedua golongan antibiotik tidak menunjukkan perbedaan bermakna terhadap luaran terapi muntah $(p=0,178)$, nyeri pinggang $(p=1,000)$, nyeri berkemih $(p=0,587)$, dan lama rawat inap $(p=0,364)$. Sedangkan kedua golongan antibiotik menunjukkan perbedaan bermakna terhadap luaran terapi suhu badan $(p=0,001)$ dan lekosit urin $(p=0,001)$. Antibiotik golongan fluoroquinolon memiliki rata-rata lama rawat inap lebih cepat 5,42 hari dibandingkan golongan sefalosporin generasi ke-3. Efektivitas antara kedua kelompok menunjukkan perbedaan yang bermakna $(\mathrm{p}<0,05)$ terhadap suhu badan dan lekosit urin, namun kedua kelompok tidak menunjukkan perbedaan yang bermakna $(p>0,05)$ terhadap luaran terapi muntah, nyeri pinggang, nyeri berkemih, dan lama rawat inap.
\end{abstract}

Kata kunci: infeksi saluran kemih (ISK), sefalosporin generasi ke-3, fluroquinolon, lama rawat inap

ABSTRACT: One of the most common infectious diseases in a hospital is urinary tract infection. Incorrect selection of antibiotics can lead to resistance growth and multiple microbial resistance to antibiotics that have an impact on increased morbidity, mortality, and health costs. This study aims to evaluate the effectiveness and comparison of duration of 3rd generation cephalosporin antibiotics and fluoroquinolone in inpatient installation of PKU Muhammadiyah Hospital Yogyakarta. This study used a retrospective cohort design in UTI patients from January 2015 to December 2017. All patient data meeting the inclusion criteria was taken from the patient medication records. Based on the results of the study, 66 UTI patients, 90.9\% were female and 53\% were dominated by groups $>60$ years old. The two classes of antibiotics showed no significant difference to the outcome of vomiting therapy $(p=0.178)$, low back pain $(p=1.000)$, urinary pain $(p=0.587)$, and length of hospitalization $(p=0.364)$. While the two classes of antibiotics showed significant differences to the body temperature therapy $(p=0.001)$ and urinary leukocytes $(p=0.001)$. Fluoroquinolone class antibiotics had an average length of hospitalization of 5.42 days compared with the 3rd generation cephalosporins. The effectiveness between the two groups showed a significant difference $(p<0.05)$ to body temperature and urine leukocytes, however both groups did not show significant difference $(p>0.05)$ on outcome of vomiting therapy, low back pain, urinary pain, and length of stay.

Keywords: urinary tract infection (UTI), 3rd generation cephalosporin, fluroquinolone, length of hospitalization 


\section{Pendahuluan}

Infeksi saluran kemih (ISK) adalah keadaan dimana kuman tumbuh dan berkembang biak dalam saluran kemih dalam jumlah yang bermakna. Diagnosa ISK ditegakkan berdasarkan manifestasi klinis dengan bakteriuria dan leukosituria (bermakna: $\geq 10$ / LPB atau pyuria) [1]. ISK dapat berlangsung dengan gejala simptomatis (dysuria, nyeri supra pubis, demam, nyeri pada daerah pinggang) atau tanpa gejala/asimptomatis [1,2].

Antibiotik profilaksis ialah antimikroba yang digunakan untuk mencegah infeksi sebelum infeksi bergejala. Antibiotik profilaksis diberikan $1 / 2$ jam sebelum tindakan dan boleh dilanjutkan maksimal 72 jam pasca tindakan. Sefalosporin generasi ke-3 dan fluoroquinolon merupakan antibiotik alternatif setelah co-trimoxazole atau trimethoprim untuk pasien ISK simptomatis (cystitis dan pyelonephritis). Banyaknya peresepan fluoroquinolon dan sefalosporin generasi ke-3 menyebabkan meningkatnya resistensi terhadap antibiotik spektrum luas. Keberhasilan terapi dinilai dengan berkurangnya gejala ISK simptomatis pada saat pasien masuk rumah sakit dan setelah mendapatkan terapi antibiotik selama $>72$ jam. Penilaian lama rawat inap dilakukan untuk melihat efektivitas golongan antibiotik menurunkan demam, menghilangkan disuria, menormalkan lekosit urin, dan menghilangkan bakteriuria $[1,2,3]$.

Berdasarkan hasil studi pendahuluan yang dilakukan di RS PKU Muhammadiyah Bantul, pasien ISK (N39.0) dari tahun 2013 - 2017 berjumlah 1.967 pasien dengan angka kejadian tertinggi pada tahun 2014 dengan 487 pasien. Pasien terdiri atas 1.455 pasien rawat jalan dan 512 pasien rawat inap, berdasarkan jenis kelamin terdiri atas 558 laki-laki dan 1.409 perempuan. Prevalensi ISK yang cukup tinggi dan banyaknya jenis antibiotik yang digunakan, maka peneliti memandang perlu untuk melakukan penelitian tentang penggunaan antibiotik pada pasien infeksi saluran kemih di RS PKU Muhammadiyah Yogyakarta. Hasil penelitian yang diperoleh diharapkan dapat men- jadi masukan untuk mengevaluasi standar pelayanan medis penyakit ISK di RS PKU Yogyakarta yang ada saat ini dalam rangka meningkatkan luaran terapi.

\section{Metode}

\subsection{Instrument dan sampel}

Penelitian ini menggunakan rancangan kohort retrospektif pada pasien ISK dengan menggunakan data rekam medis RS PKU Muhammadiyah Yogyakarta periode 2015 sampai dengan 2017. Data yang mendukung dalam penelitian ini yaitu nama, umur, data diagnosis rumah sakit, data hasil pemeriksaan urin lengkap sebelum dan setelah pemberian antibiotik, manifestasi klinik pasien dan lama rawat inap.

Data subjek diambil sesuai dengan kriteria inklusi yang meliputi: (1) pasien $\geq 18$ tahun dengan diagnosa Urinary Tract Infection Symptomatic (cystitis dan pyelonephritis) yang dirawat inap di RS PKU Muhammadiyah Yogyakarta, (2) pasien rawat inap dan mendapatkan terapi antibiotika golongan sefalosporin generasi ke-3 maupun fluoroquinolon selama $>72$ jam, (3) pasien ISK dengan leukosituria ( $>5 / \mathrm{lpd}$ ) menyesuaikan nilai standar laboratorium RS PKU Muhammadiyah Yogyakarta, sedangkan untuk kriteria eksklusinya yaitu: (1) rekam medis yang tidak lengkap, (2) Pasien dengan kondisi hamil, (3) pasien dengan gangguan sistem imun infeksi lainnya misalnya pasien dengan diagnosis HIV/ AIDS, diare, ISPA.

\subsection{Variabel penelitian}

\subsubsection{Variabel bebas}

Variabel bebas dalam penelitian ini yaitu penggunaan antibiotik sefalosporin generasi ke-3 dan fluoroquinolon pada pasien infeksi saluran kemih.

\subsubsection{Variabel terikat}

Variabel terikat dalam penelitian ini yaitu luaran terapi yang meliputi suhu, muntah, nyeri 
pinggang, nyeri berkemih, leukosituria, dan lama rawat inap.

\subsubsection{Variabel perancu}

Variabel perancu dalam penelitian ini yaitu penyakit penyerta pasien, riwayat alergi pasien.

\subsubsection{Analisis data}

Uji karakteristik masing-masing penggunaan antibiotik menggunakan analisis univariat meliputi jenis kelamin dan umur. Uji statistik untuk jenis hipotesis komparatif kategorik tidak berpasangan menggunakan uji Fisher's untuk data nominal. Jenis hipotesis komparatif numerik berpasangan menggunakan uji Paired T-test dan Wilcoxon untuk data interval dan rasio, sedangkan jenis hipotesis komparatif numerik tidak berpasangan menggunakan uji Mann-Whitney untuk data rasio.

\section{Hasil dan pembahasan}

\subsection{Karakteristik pasien}

Karakteristik subjek penelitian yang dibahas meliputi data jenis kelamin dan kelompok umur. Pasien dengan ISK yang masuk dalam kriteria inklusi yang dianalisis sebanyak 66 pasien, yang terdiri atas 47 pasien kelompok golongan sefalosporin generasi ke-3 dan 19 pasien kelompok golongan fluoroquinolon. Karakteristik pasien yang menerima antibiotika tersebut dapat dilihat pada Tabel 1. Berdasarkan jenis kelamin, jumlah pasien ISK yang diterapi dengan antibiotik golongan sefalosporin generasi ke-3 sebanyak 60 pasien $(90,9 \%)$ untuk jenis kelamin perempuan dan 6 pasien $(9,1 \%)$ untuk jenis kelamin laki-laki. Hal ini sejalan dengan hasil penelitian yang dilaporkan oleh Samirah, yang melaporkan bahwa perempuan lebih sering menderita ISK dibandingkan laki-laki. Hal ini dapat terjadi karena secara anatomi uretra perempuan memiliki panjang sekitar $4 \mathrm{~cm}$ dan terletak di dekat anus. Hal ini menjadikannya lebih rentan untuk terkena kolonisasi bakteri basil gram negatif. Karenanya, perempuan lebih rentan terkena ISK. Berbeda dengan laki-laki yang struktur uretranya lebih panjang dan memiliki kelenjar prostat yang sekretnya mampu melawan bakteri, sehingga ISK pun lebih jarang ditemukan [4].

Berdasarkan umur, jumlah pasien ISK yang diterapi dengan antibiotik golongan sefalosporin generasi ke-3 sebesar 31 pasien (47\%) untuk kelompok umur 18-59 tahun dan dengan terapi fluoroquinolon sebanyak 35 pasien (53\%) untuk kelompok umur $>60$ tahun. Hal ini menunjukkan bahwa angka kejadian ISK meningkat seiring bertambahnya usia.

\subsection{Perbedaan efektivitas golongan antibiotik terhadap luaran terapi suhu}

Pengukuran suhu sebelum terapi antibiotik

Tabel 1. Karakteristik pasien ISK di RS PKU Muhammadiyah Yogyakarta yang menerima terapi antibiotika

\begin{tabular}{|c|c|c|c|c|}
\hline \multirow[t]{2}{*}{ Karakteristik } & \multirow[t]{2}{*}{ Jumlah total (\%) } & \multirow[t]{2}{*}{ Mean \pm SD } & \multirow{2}{*}{$\begin{array}{l}\begin{array}{l}\text { Golongan } \\
\text { sefalosporin } \\
\text { generasi ke-3 }\end{array} \\
\mathbf{n ( \% )}\end{array}$} & Fluoroquinolon \\
\hline & & & & n (\%) \\
\hline \multicolumn{5}{|l|}{ Jenis Kelamin } \\
\hline Laki-laki & $6(9,1)$ & \multirow{2}{*}{$1,91 \pm 0,290$} & $6(100)$ & $0(0)$ \\
\hline Perempuan & $60(90,9)$ & & $41(68,3)$ & $19(31,7)$ \\
\hline \multicolumn{5}{|l|}{ Umur } \\
\hline 18-59 tahun & $31(47)$ & \multirow{2}{*}{$1,53 \pm 0,503$} & $22(71)$ & $9(29)$ \\
\hline$>60$ tahun & $35(53)$ & & $25(71,4)$ & $10(28,6)$ \\
\hline
\end{tabular}


dilakukan pada saat pasien masuk rumah sakit dan pengukuran suhu selanjutnya dilakukan pada saat mendapatkan terapi antibiotik selama $>72$ jam. Tabel 2 menunjukkan hasil Paired T-test ( $p=0,001)$, karena nilai $\mathrm{p}<0,005$, secara statistik terdapat perbedaan bermakna antara suhu sebelum dan setelah terapi golongan sefalosporin generasi ke-3 dan golongan fluoroquinolon. Antibiotik golongan sefalosporin generasi ke-3 menunjukkan penurunan suhu lebih tinggi dibandingkan fluoroquinolon sebesar $0,82^{\circ} \mathrm{C}$ dengan simpangan baku 1,11. Sedangkan golongan fluoroquinolon menunjukkan penurunan suhu sebesar $0,67^{\circ} \mathrm{C}$ dengan simpangan baku 0,68 . Antibiotik golongan sefalosporin generasi ke-3 dan fluoroquinolon mempunyai median yang sama yaitu $0,60^{\circ} \mathrm{C}$. Range golongan sefalosporin generasi ke-3 lebih tinggi dibandingkan dengan fluoroquinolon yaitu $4,8^{\circ} \mathrm{C}$ untuk sefalosporin generasi ke-3 dan fluoroquinolon $2,8^{\circ} \mathrm{C}$. Range dapat diperoleh dengan cara nilai maksimum suhu dikurangi nilai minimum suhu.

\subsection{Perbedaan efektivitas golongan antibiotik terhadap luaran terapi muntah}

Pemeriksaan gejala klinis muntah dilakukan pada saat pasien masuk rumah sakit sebagai data awal dan pemeriksaan selanjutnya pada hari terakhir perawatan dan dinyatakan boleh pulang oleh dokter penanggung jawab pasien sebagai data akhir. Tabel 3 menunjukkan hasil uji Fisher's $(\mathrm{p}=0,178)$, karena nilai $\mathrm{p}>0,05$, secara statistik tidak terdapat perbedaan bermakna antara golongan sefalosporin generasi ke-3 dan golongan fluoroquinolon terhadap gejala klinis muntah. Adapun besar bedanya dapat dilihat nilai $\mathrm{OR}=6,22$, artinya pasien yang mendapatkan terapi sefalosporin generasi ke-3 mempunyai perbaikan gejala klinis muntah 6,22 kali lebih baik dibandingkan fluoroquinolon.

Tabel 2. Perbedaan efektivitas suhu antibiotik golongan sefalosporin generasi ke-3 (injeksi) dan golongan fluoroquinolon (injeksi)

\begin{tabular}{|c|c|c|c|c|c|}
\hline Golongan & Rerata \pm SD & Selisih \pm SD & Median & Range & Nilai p \\
\hline \multicolumn{6}{|c|}{ Sefalosporin generasi ke-3 $(n=47)$} \\
\hline Suhu sebelum terapi & $37,24 \pm 1,07$ & $0,82 \pm 1,11$ & 0,600 & 4,8 & $<0,001^{*}$ \\
\hline Suhu setelah terapi & $36,41 \pm 0,33$ & & & & \\
\hline \multicolumn{6}{|l|}{ Fluoroquinolon $(n=19)$} \\
\hline Suhu sebelum terapi & $37,14 \pm 0,63$ & $0,67 \pm 0,68$ & 0,600 & 2,8 & $<0,001^{*}$ \\
\hline Suhu setelah terapi & $36,46 \pm 0,38$ & & & & \\
\hline
\end{tabular}

*Paired T-test

Tabel 3. Perbedaan efektivitas gejala klinis muntah dengan antibiotik golongan sefalosporin generasi ke-3 (injeksi) dan golongan fluoroquinolon (injeksi)

\begin{tabular}{llllll}
\hline \multirow{2}{*}{ No. } & \multirow{2}{*}{ Golongan } & \multicolumn{2}{c}{ Muntah } & \multicolumn{2}{c}{ Nilai $\mathrm{p}$} \\
$(\mathrm{p}<0,05)$ & \multirow{2}{*}{ OR (95\%CI) } \\
\cline { 3 - 4 } & & Normal (\%) & Tidak normal (\%) & & \\
\hline 1. & Sefalosporin generasi ke-3 & $28(96,6)$ & $1(3,4)$ & $0,178^{*}$ & $6,22(0,53-76,96)$ \\
2 & Fluoroquinolon & $9(81,8)$ & $2(18,2)$ & & \\
\hline & Total (\%) & $37(92,5)$ & $3(7,5)$ & $40(100)$ & \\
\hline
\end{tabular}

${ }^{*}$ Fisher's 


\subsection{Perbedaan efektivitas golongan antibiotik terhadap luaran terapi nyeri pinggang}

Pemeriksaan gejala klinis nyeri pinggang dilakukan pada saat pasien masuk rumah sakit sebagai data awal dan pemeriksaan selanjutnya pada hari terakhir perawatan dan dinyatakan boleh pulang oleh dokter penanggung jawab pasien sebagai data akhir. Tabel 4 menunjukkan hasil uji Fisher's $(\mathrm{p}=1,00)$, karena nilai $\mathrm{p}>0,05$, secara statistik tidak terdapat perbedaan bermakna antara golongan sefalosporin generasi ke-3 dan golongan fluoroquinolon terhadap gejala klinis nyeri pinggang. Adapun besar bedanya dapat dilihat nilai $\mathrm{OR}=1,60$, artinya pasien yang mendapatkan terapi sefalosporin generasi ke-3 mempunyai perbaikan gejala klinis muntah 1,60 kali lebih baik dibandingkan fluoroquinolon

\subsection{Perbedaan efektivitas golongan antibiotik terhadap luaran terapi nyeri berkemih}

Pemeriksaan gejala klinis nyeri berkemih dilakukan pada saat pasien masuk rumah sakit sebagai data awal dan pemeriksaan selanjutnya pada hari terakhir perawatan dan dinyatakan boleh pulang oleh dokter penanggung jawab pasien sebagai data akhir. Tabel 5 menunjukkan hasil uji Fisher's ( $\mathrm{p}=0,587)$, karena nilai $\mathrm{p}>0,05$, secara statistik tidak terdapat perbedaan bermakna antara golongan sefalosporin generasi ke-3 dan golongan fluoroquinolon terhadap gejala klinis nyeri berkemih. Adapun besar bedanya dapat dilihat nilai $\mathrm{OR}=2,20$ artinya pasien yang mendapatkan terapi sefalosporin generasi ke-3 mempunyai perbaikan gejala klinis muntah 2,20 kali lebih baik dibandingkan fluoroquinolon.

Menurut penelitian Wagenlehner, untuk pengobatan sistisis, menunjukkan bahwa kotrimoksazol/trimethoprim sama efektifnya dengan fluoroquinolon, fosfomycin trometamol, nitrofurantoin, serta pivmecillinam, dan antibiotik ini lebih efektif daripada sefalosporin dan aminopenicillin. Untuk terapi oral pielonefritis, menunjukkan efektivitas fluoroquinolon yang lebih besar dibandingkan sefalosporin dan kotrimoksazol/ trimethoprim. Pada lansia, jika pasien diduga infeksi bacillary gram negatif, dianjurkan sefalosporin generasi ketiga atau piperacillin-tazobactam (dengan atau tanpa aminoglikosida) atau

Tabel 4. Perbedaan efektivitas gejala klinis nyeri pinggang dengan antibiotik golongan sefalosporin generasi ke-3 (injeksi) dan golongan fluoroquinolon (injeksi)

\begin{tabular}{llllll}
\hline \multirow{2}{*}{ No. } & \multirow{2}{*}{ Golongan } & \multicolumn{2}{c}{ Nyeri Pinggang } & Nilai $\mathrm{p}$ & \multirow{2}{*}{ OR (95\%CI) } \\
\cline { 3 - 4 } & & \multicolumn{1}{c}{ Normal (\%) } & Tidak normal (\%) & $(\mathrm{p}<0,05)$ & \\
\hline 1. & Sefalosporin generasi ke-3 & $12(80,0)$ & $3(20,0)$ & $1,000^{*}$ & \multirow{2}{*}{$1,60(0,20-12,69)$} \\
2 & Fluoroquinolon & $5(71,4)$ & $2(28,6)$ & & \\
\hline & Total (\%) & $17(77,3)$ & $5(22,7)$ & $22(100)$ & \\
\hline
\end{tabular}

*Fisher's

Tabel 5. Perbedaan efektivitas gejala klinis nyeri berkemih dengan antibiotik golongan sefalosporin generasi ke-3 (injeksi) dan golongan fluoroquinolon (injeksi)

\begin{tabular}{|c|c|c|c|c|c|}
\hline \multirow{2}{*}{ No. } & \multirow{2}{*}{ Golongan } & \multicolumn{2}{|c|}{ Nyeri Berkemih } & \multirow{2}{*}{$\begin{array}{c}\text { Nilai } p \\
(p<0,05)\end{array}$} & \multirow{2}{*}{ OR $(95 \% \mathrm{CI})$} \\
\hline & & Normal (\%) & Tidak normal (\%) & & \\
\hline 1. & Sefalosporin generasi ke-3 & $11(84,6)$ & $2(15,4)$ & \multirow{2}{*}{$0,587^{*}$} & \multirow{2}{*}{$2,20(0,23-20,39)$} \\
\hline 2 & Fluoroquinolon & $5(71,4)$ & $2(28,6)$ & & \\
\hline & Total (\%) & $16(80,0)$ & $4(20,0)$ & $20(100)$ & \\
\hline
\end{tabular}

*Fisher's 
fluoroquinolon (misalnya ciprofloxacin atau levofloxacin). Setelah data kultur tersedia, terapi antibiotik dapat disesuaikan $[5,6]$.

Berbeda dengan penelitian yang dilakukan Wilbur, dengan membandingkan ertapenem dengan ceftriaxone diikuti dengan terapi oral ciprofloxacin. Setelah hari ke 5-9 perawatan, 229 (89,5\%) pasien yang menerima ertapenem dan $204(91,1 \%)$ pasien yang menerima ceftriaxone memiliki respons mikrobiologis yang menguntungkan (interval kepercayaan 95\%, -7,4 sampai 4,0 ), yang menunjukkan bahwa hasil pada kedua kelompok perlakuan itu setara. Dalam analisis gabungan ini, ertapenem adalah terapi yang sangat efektif untuk pengobatan ISK yang rumit pada orang dewasa dengan penyakit sedang sampai berat. Sedangkan penelitian yang dilakukan Hobbs, dengan membandingkan cefazolin dengan ceftriaxone terhadap 184 pasien dengan pielonefritis yang tingkat kesembuhan $82,1 \%$ untuk kelompok cefazolin dan $84,0 \%$ untuk kelompok ceftriaxone (perbedaan absolut 1,9\%, 95\% CI - 12,8\% sampai 16,5\%, p=0,80). Keuntungan golongan sefalosporin generasi ke-3 ialah spektrum aktivitas luas pada gram negatif dan enterobakteri, bakteri multipel resisten, tetapi kurang aktif terhadap kokus gram positif $[7,8,9]$.

Pasien dengan gejala klinis disuria dengan rasa sakit, terbakar, atau ketidaknyamanan saat buang air kecil, lebih sering terjadi pada perempuan daripada laki-laki. Meskipun infeksi saluran kemih merupakan penyebab paling sering disuria, pengobatan empiris dengan antibiotik tidak selalu tepat, sehingga pengobatannya berdasarkan kondisi dan diagnosis pasien [10]. Hal ini sejalan dengan hasil penelitian bahwa penggunaan antibiotik sefalosporin generasi ke-3 dan fluoroquinolon tidak berbeda bermakna terhadap gejala klinis muntah, nyeri pinggang, dan nyeri berkemih pada pasien ISK. Hal ini dikarenakan gejala-gejala tersebut merupakan symptoms ISK dan diterapi berdasarkan kondisi dan gejala klinis pasien.

\subsection{Perbedaan efektivitas golongan antibiotik terhadap lekosit urin}

Pengukuran lekosit urin sebelum terapi antibiotik dilakukan pada saat pasien masuk rumah sakit dan pengukuran lekosit selanjutnya dilakukan pada saat mendapatkan terapi antibiotik selama $>72$ jam. Tabel 6 menunjukkan hasil uji t-test paired dan Wilcoxon $(\mathrm{p}=0,001)$ karena nilai $\mathrm{p}<0,005$, secara statistik terdapat perbedaan bermakna antara lekosit sebelum dan sesudah terapi golongan sefalosporin generasi ke-3 dan golongan fluoroquinolon. Antibiotik golongan fluoroquinolon menunjukkan penurunan lekosit urin lebih cepat dibandingkan sefalosporin ge-

Tabel 6. Perbedaan efektivitas lekosit urin dengan antibiotik golongan sefalosporin generasi ke-3 (injeksi) dan golongan fluoroquinolon (injeksi)

\begin{tabular}{|c|c|c|c|c|c|}
\hline Golongan & Rerata \pm SD & Selisih \pm SD & Median & Range & Nilai p \\
\hline \multicolumn{6}{|c|}{ Sefalosporin generasi ke-3 $(n=47)$} \\
\hline Lekosit sebelum terapi & $28,63 \pm 16,66$ & $15,52 \pm 16,82$ & 13,500 & 82,5 & $<0,001^{\mathrm{a}}$ \\
\hline Lekosit setelah terapi & $13,11 \pm 16,65$ & & & & \\
\hline \multicolumn{6}{|l|}{ Fluoroquinolon $(n=19)$} \\
\hline Lekosit sebelum terapi & $31,23 \pm 20,44$ & $16,97 \pm 18,04$ & 11,000 & 57,5 & $<0,001^{\mathrm{b}}$ \\
\hline Lekosit setelah terapi & $14,26 \pm 17,65$ & & & & \\
\hline
\end{tabular}


nerasi ke-3 sebesar 16,97/lpb dengan simpangan baku 18,043, sedangkan golongan sefalosporin generasi ke-3 menunjukkan penurunan lekosit urin sebesar 15,52/lpb dengan simpangan baku 16,825 . Antibiotik golongan sefalosporin generasi ke-3 dan fluoroquinolon mempunyai median masing-masing 13,50/lpb dan 11,00/lpb. Range golongan sefalosporin generasi ke-3 lebih tinggi dibandingkan dengan fluoroquinolon yaitu 82,5/ lpb untuk sefalosporin generasi ke-3 dan fluoroquinolon 57,5/lpb. Range dapat diperoleh dengan cara nilai maksimum lekosit urin dikurangi nilai minimum lekosit urin.

Pemberian antibiotik dapat mempengaruhi perubahan lekosituria sebelum dan setelah terapi. Menurut penelitian Tori, sebanyak 91 pasien yang mendapatkan terapi antibiotik amkoksisilin, asam pipemidinat, asam nalidiksat, ciprofloxacin, dan oflloxacin menyimpulkan bahwa kelima antibiotik menghasilkan efektifitas yang sama atau tidak ada perbedaan signifikan $(p=0,634>$ $0,05)$. Pada beberapa kasus ISK katerisasi, tidak terdapat perbedaan keefektifan antara Levofloxacin oral $750 \mathrm{mg}$ dengan ciprofloxacin oral 750 mg dalam menurunkan insiden leukosituria sebagai terapi profilaksis terhadap ISK pada pasien yang dipasang Foley catheter $[1,11,12]$.

\subsection{Perbedaan efektivitas golongan antibiotik terhadap lekosit urin}

Lama rawat inap dihitung sejak pasien masuk rumah sakit hingga keluar rumah sakit dan tercatat dalam rekam medik sampai pasien di- nyatakan sembuh dan dibolehkan pulang oleh DPJ pasien dan tercatat di rekam medik pasien.

Tabel 7 menunjukkan hasil uji Mannwhitney $(\mathrm{p}=0,364)$, karena nilai $\mathrm{p}>0,005$, secara statistik tidak terdapat perbedaan bermakna antara lama rawat inap dengan golongan sefalosporin generasi ke-3 dan golongan fluoroquinolon. Antibiotik golongan fluoroquinolon menunjukkan lama rawat inap lebih cepat dibandingkan sefalosporin generasi ke-3 selama 5,42 hari dengan simpangan baku 1,805, sedangkan golongan sefalosporin generasi ke-3 menunjukkan lama rawat inap selama 5,83 hari dengan simpangan baku 1,592. Antibiotik golongan sefalosporin generasi ke-3 dan fluoroquinolon mempunyai median masing-masing 6 hari dan 5 hari. Range golongan sefalosporin generasi ke-3 sama dengan fluoroquinolon yaitu 6 hari. Range dapat diperoleh dengan cara nilai maksimum lama rawat inap dikurangi nilai minimum lama rawat inap.

Perbedaan lama rawat inap di rumah sakit yang berbeda dapat disebabkan oleh beberapa pasien masih belum mengalami perbaikan gejala. Standard perawatan ISK adalah selama 3 hari. Dalam masa rawat inap selama 3 hari tersebut diharapkan dapat menurunkan derajat demam, menghilangkan disuria, menormalkan lekosit urin, dan menghilangkan bakteriuria [13].

Penelitian yang dilakukan Triono (2016), yang membandingkan lama rawat inap antara antibiotik sefalosporin dengan quinolon mendapatkan hasil bahwa lama perawatan ISK menggunakan terapi antibiotik golongan sefalosporin $4,57 \pm 2,07$

Tabel 7. Perbedaan efektivitas lama rawat inap dengan antibiotik golongan sefalosporin generasi ke-3 (injeksi) dan golongan fluoroquinolon (injeksi)

\begin{tabular}{llll}
\hline \multirow{2}{*}{ Lama rawat inap } & \multicolumn{2}{c}{ Terapi antibiotik } & \multirow{2}{*}{ Nilai p } \\
\cline { 2 - 3 } & \multicolumn{2}{c}{ Sefalosporin generasi ke-3 } & Fluoroquinolon \\
\hline Mean $\pm S D$ & $5,83 \pm 1,592$ & $5,42 \pm 1,805$ & $0,364^{*}$ \\
Median & 6,00 & 5,00 & \\
Range & 6 & 6 & \\
\hline
\end{tabular}

*Mann-whitney 
hari, dan lama perawatan menggunakan antibiotik golongan quinolon 3,95 $\pm 1,51$ hari, kedua kelompok tersebut tidak berbeda bermakna ditunjukkan dengan uji statistik Mann-whitney ( $p>0,05)$ [14].

Penelitian yang dilakukan Nurul (2017), yang membandingkan penggunaan seftriakson dan levofloxacin terhadap lama rawat inap menunjukkan hasil lama rawat inap pasien Levofloxacin adalah 2,90 $\pm 1,44$ hari sedangkan pasien yang menggunakan seftriakson adalah 4,66 $\pm 2,43$ hari dengan nilai $\mathrm{p}$ sebesar 0,016 . Serta penelitian selanjutnya yang menyatakan lama rawat inap pasien dengan diagnosa ISK yang menggunakan cefotaxime adalah 5,30 \pm 1,121 hari dan yang menggunakan levofloxacin adalah 3,59 $\pm 0,927$ hari. Dari penelitian ini dapat disimpulkan bahwa terdapat perbedaan lama rawat inap pada pasien dengan diagnosa ISK yang menggunakan cefotaxime dan levofloxacin $[15,16]$.

\section{Keterbatasan Penelitian}

Pemilihan terapi antibiotik tidak berdasarkan tingkat keparahan (uretritis, sistisis, pielonefritis) sehingga berpengaruh pada jumlah antibiotik yang digunakan (sefalosporin generasi ke- $3 \mathrm{~N}=47$ dan fluoroquinolon $\mathrm{N}=19$ ). Peneliti mengekslusi subjek yang cukup banyak akibat dari kurangnya pemeriksaan lekosit urin ulang pada subjek penelitian.

\section{Kesimpulan}

Perbandingan efektivitas antibiotik golongan sefalosporin generasi ke-3 dan antibiotik golongan fluoroquinolon menunjukkan tidak terdapat perbedaan bermakna terhadap luaran terapi muntah nyeri pinggang, nyeri berkemih, dan lama rawat inap ( $p>0,05)$, sedangkan antibiotik golongan sefalosporin generasi ke-3 dan antibiotik golongan fluoroquinolon menunjukkan perbedaan bermakna antara luaran terapi suhu badan dan lekosit urin $(\mathrm{p}<0,005)$.

\section{Daftar Pustaka}

1. Sofyan M, Alvarino A, Erkadius E. Perbandingan Levofloxacin dengan Ciprofloxacin Peroral dalam Menurunkan Leukosituria Sebagai Profilaksis Isk pada Kateterisasi di RSUP. Dr. M. Djamil Padang. Jurnal Kesehatan Andalas. 2014;3(1).

2. Grabe M, Johansen TEB, Botto H, Wult B, et all. Guideline on urological Infections. European Association of Urology; 2015:41-2.

3. Cassier P, Lallechere S, Aho S, Astruc K, Neuwirth C, Piroth L, Chavanet P. Cephalosporin and fluoroquinolone combinations are highly associated with CTX-M $\beta$-lactamase-producing Escherichia coli: a case-control study in a French teaching hospital. Clinical Microbiology and Infection. 2011;17(11):1746-51.

4. Samirah D, Windarwati H. Pola dan sensitivitas kuman di penderita infeksi saluran kemih. Indonesian Journal of Clinical Pathology and Medical Laboratory. 2006;12(3):110-3.

5. Wagenlehner FM, Schmiemann G, Hoyme U, et all. Epidemiologie, Diagnostik, Therapie und Management unkomplizierter bakterieller ambulant erworbener Harnwegsinfektionen bei erwachsenen Patienten. S3-Leitlinie AWMF-Register. 2010(043/044). www.uniduesseldorf.de/ AWMF/. Diakses pada 06 Februari 2018.

6. Malini S, Donald K. Antibiotic agents in the elderly. Infectious Disease Clinics North America. 2004;18:533-49.

7. Wells WG, Woods GL, Jiang Q Gesser RM. Treatment of complicated urinary tract infection in adults: combined analysis of two randomized, double-blind, multicentre trials comparing ertapenem and ceftriaxone followed by appropriate oral therapy. Journal of Antimicrobial Chemotherapy. 2004;53(suppl_2):ii67-74.

8. Hobbs AL, Shea KM, Daley MJ, Huth RG, Jaso TC, Bissett J, Hemmige V. Are first-generation cephalosporins obsolete? A retrospective, non-inferiority, cohort study comparing empirical therapy with cefazolin versus ceftriaxone for acute pyelonephritis in hospitalized patients. Journal of Antimicrobial Chemotherapy. 2016;71(6):1665-71. 
9. Riaz B, Khatoon H. Evaluation of the use of cephalosporin antibiotics in pediatrics. Journal of $\mathrm{Ap}$ plied Pharmaceutical Science. 2013;3(4):63.

10. Bremnor JD, Sadovsky R. Evaluation of dysuria in adults. American family physician. 2002;65(8):1589-98.

11. Mutiarawati. Evaluasi Keberhasilan Terapi Kasus Infeksi Saluran Kemih Dengan Penyakit atau Tanpa Penyakit Penyerta Di Instalasi Rawat Inap RS Panti Rapih Yogyakarta periode 2014. Tesis. Universitas Gadjah Mada, Yogyakarta; 2014.

12. Tori. Evaluasi penggunaan antibiotika pada penderita diduga infeksi saluran kemih di unit rawat jalan RSK Ngesti Waluyo Parakan periode Januari 2001-Juni 2002. Tesis. Program Pascasarjana Universitas Gadjah Mada, Yogyakarta. 2003.

13. Rasjidi I. Panduan penatalaksanaan Infeksi pada
Traktus Genitalis dan Urinarius. Jakarta: EGC; 2011. 14. Triono A, Purwoko AE. Efektifitas Antibiotik Golongan Sefalosporin dan Kuinolon terhadap Infeksi Saluran Kemih. Mutiara Medika: Jurnal Kedokteran dan Kesehatan. 2016;12(1):6-11.

15. Anisa NK. Perbandingan Efektivitas Antara Penggunaan Seftriakson dan Levofloxacin terhadap Lama Rawat Inap Pada Pasien Infeksi Saluran Kemih (ISK) di Rumah Sakit Islam Sultan Agung Semarang Periode Agustus 2014 - Agustus 2016. Skripsi. Universitas Islam Sultan Agung, Semarang; 2017.

16. Yuliana W. Perbedaan Efektivitas antara Pemakaian Cefotaxime dengan Levofloxacin Berdasarkan Lama Rawat Inap Terhadap Pasien Infeksi Saluran Kemih (ISK). Skripsi. Universitas Islam Sultan Agung, Semarang. 2015. 